Section Editors

David C. Spencer, MD

Steven Karceski, MD

Steven Karceski, MD

\section{Epilepsy and mood}

In their article "Temporal trends in new exposure to antiepileptic drug monotherapy and suicide-related behavior," Dr. Pugh and colleagues ${ }^{1}$ explore the link between antiepileptic drugs (AEDs) and suicide. This has been an important and worrisome topic for people with epilepsy. In short, a patient may wonder, "Will the medications I take cause other problems?" This is so important that a Patient Page addressed this same topic in the summer of 2010, when the article by Dr. Andersohn et al. ${ }^{2}$ was published in Neurology ${ }^{\circledR}$.

AEDs are used to treat different medical conditions, including depression, bipolar disorder, chronic pain, and epilepsy. It has long been shown that seizures, epilepsy, mood problems, and suicide-related behaviors overlap. An analysis of many AED trials suggests that the medication itself may be contributing to this problem. However, many studies, including the Food and Drug Administration (FDA)'s review of this association, have lumped all antiseizure medications together.

As a result of their analysis, in early 2008, the FDA issued a safety alert concerning all AEDs. The alert was based on an analysis of 199 studies. In these studies, an AED was compared to placebo. When grouped together, the analysis showed that there was an increased risk of suicidal thoughts and behavior (suicide-related behavior [SRB]) in people who were taking an AED.

Because the FDA grouped all seizure medications together, it was not possible to determine whether there were specific medications that were more likely to cause mood problems. Dr. Andersohn and colleagues set out to answer this question in 2010. Although their study suggests that levetiracetam is more likely to cause suicidal behavior/self-harm, the authors also made it clear that we need to study this problem more carefully.

However, the story may be more complicated than "Which medication causes a problem?" For instance, in 2006, Simon et al. ${ }^{3}$ found that when using an AED to treat depression, the SRB peaked just before the AED was given. After taking the AED, the SRB decreased.

The data seem confusing. Is there an association between AEDs and SRB or not? These studies help us to answer this question. For instance, if a group of people taking AEDs is asked whether they have ever experienced SRB, the answer may be yes. However, if asked when the SRB occurred, it was more likely to happen just before treatment was started. In other words, the treatment was started as a treatment for the SRB (and the underlying disorder, such as depression or bipolar disorder).

HOW WAS THE STUDY DONE? Dr. Pugh and colleagues carried the research by Dr. Simon et al. further. They used the Veterans Health Administration database to identify older veterans (over 65 years) who started taking an AED between October 2003 and September 2006. In order to understand how the SRB was related to the start of taking the AED, she evaluated the records of the veterans for 1 year before and 1 year after the AED was first taken. Veterans who were included were those who were taking a new AED. Further, they had to be taking only one AED.

Pugh et al. looked at veterans who were taking one of the available AEDs: phenobarbital, phenytoin, carbamazepine, valproate, gabapentin, lamotrigine, levetiracetam, oxcarbazepine, tiagabine, topiramate, or pregabalin. Since the study was for 1 year before and after starting an AED, each person was followed for 24 months. Pugh et al. looked at each month. They analyzed the occurrence of SRB in each of the 24 months, looking for a time period when SRB was the highest.

From 2003 to 2006, almost 2.5 million veterans were treated for medical illnesses. Pugh et al. identified 90,230 who had received a first treatment with a single AED. As expected, most (97.3\%) were men. Their average age was 75.1 years. Most of the veterans $(76.2 \%)$ started taking gabapentin. Much less often, they started taking valproate, phenytoin, carbamazepine, or topiramate. Fewer than $0.1 \%$ took the other AEDs listed.

Many of the veterans had experienced SRB before starting the AED. Very often, they had depression, anxiety, bipolar disorder, posttraumatic stress disorder, substance abuse, or chronic pain. The veterans who had depression or bipolar disorder were much more likely to have SRB. Those who had epilepsy or chronic pain did not seem to have an increased risk of SRB. 
WHAT DID THE STUDY SHOW? Pugh et al. found that veterans receiving a first AED were most likely to experience SRB in the month before starting the medication. In fact, the rates of SRB were much lower in all of the other months (before and after starting treatment with an AED). There were several limitations to their study. Pugh et al. were not able to determine whether a specific medication causes SRB. Further, their study looked at veterans and may not be applicable to older women.

WHY IS THE STUDY IMPORTANT? The association between SRB and AEDs has been known for many years. However, the association has been a difficult one to study. Most of the studies have lumped the medications together. This has led to statements about the entire class of medications known as AEDs: this is also called a class effect. It has been difficult to identify whether a single medicine (or perhaps a small number of AEDs) is responsible for the SRB. Further, few studies have examined the time course of taking a medication and the development of SRB. If all of the SRB occurred after taking the medication, there would be a clearer relationship between the two. The fact that 2 studies have shown that SRB peaks before starting the AED suggests the opposite: that the AED made the SRB better. In short, the AED helped the illness that caused the SRB in the first place.

\section{REFERENCES}

1. Pugh MJV, Hesdorffer D, Wang C-P, et al. Temporal trends in new exposure to antiepileptic drug monotherapy and suicide-related behavior. Neurology 2013;81:1900-1906.

2. Andersohn F, Schade R, Willich SN, Garbe E. Use of antiepileptic drugs in epilepsy and the risk of self-harm or suicidal behavior. Neurology 2010;75:335-340.

3. Simon GE, Savarino J, Operskalski B, et al. Suicide risk during antidepressant treatment. Am J Psychiatry 2006; 163:41-47. 
Section Editors

David C. Spencer, MD

Steven Karceski, MD

\title{
Seizures, epilepsy, and mood
}

\author{
How they overlap
}

Adapted from: Karceski S. Epilepsy and mood. Neurology 2010;75:e12-e15.

Mood disorders and epilepsy overlap. ${ }^{1}$ This is especially true when a person has seizures that do not stop with antiseizure medications. When seizures are not completely controlled with medicine, they are called refractory. A total of $30 \%-50 \%$ of people with refractory seizures also have some sort of mood problem. They may have depression, anxiety, or both.

Because epilepsy and mood problems overlap, they are called comorbid conditions. By definition, comorbidity means that the associated illness occurs more often than would be expected compared to populations of patients who do not have the other illness. In other words, if $10 \%$ of people have depression, we would expect that $10 \%$ of people with epilepsy also would have depression. However, the number is higher (up to $50 \%$ ). In other words, the overlap cannot be explained by chance. There must be something else that links the two.

However, comorbidity does not imply causality. ${ }^{2}$ Even though the 2 illnesses occur together, this does not mean that one causes the other. What is more likely is that the 2 illnesses share a common cause. In other words, the cause of one illness is also the cause of the other. Although not fully understood, an abnormality of neurotransmitters may be the link that connects mood with epilepsy. One thing that is very clear is that the comorbid illness can significantly affect quality of life. In fact, the quality of life of people with epilepsy is influenced more by the presence of depression than the frequency of their seizures. ${ }^{3}$

MOOD DISORDERS AND EPILEPSY The association between depression and anxiety has been observed for centuries: Hippocrates in 400 BC said, "Melancholics ordinarily become epileptics." ${ }^{\text {In }}$ In more recent years, this association has been carefully studied. Scientists have tried to better understand how the 2 illnesses are related. In addition, they have tried to figure out what causes both. In doing this, they hope to be able to develop better therapies or treatments.

The first step in figuring this out was to determine the severity of the problem. In 2005, a survey was sent to more than 85,000 people. The survey asked questions about chronic illnesses like epilepsy, migraine, asthma, and diabetes. The survey also asked questions about mood, specifically bipolar disorder. ${ }^{5}$ The goal was to compare the rates of mood problems in people with epilepsy (1,236 respondents), migraine (8,994 respondents), asthma (7,951 respondents), and diabetes (7,342 respondents) vs healthy controls (57,172 respondents). Symptoms of bipolar disorder were found in $12.2 \%$ of people with epilepsy, $7.2 \%$ of migraineurs, $6.3 \%$ of patients with asthma, 3.2\% of patients with diabetes, and $1.7 \%$ of the controls. In other words, symptoms of bipolar disorder occurred at a rate 6 times higher in persons with epilepsy than in the control group.

Major depressive disorder (MDD) is defined as depression lasting for more than 2 weeks. It occurs in about $5.8 \%$ of the general population. In those with epilepsy, the number with MDD is $8 \%-48 \%$ (an average of 29\%). ${ }^{2}$ In a community-based study on people with epilepsy, the rate of depression was $37 \%$. In patients referred to an epilepsy center, the rate of depression was $50 \%$. People referred to an epilepsy center usually have refractory epilepsy. In other words, the reason that people in an epilepsy center are more likely to be depressed may relate to the severity of their epilepsy. What this means is that depression occurs 10 times more often in people with refractory epilepsy than people who have no medical illness.

The number of people who have epilepsy and anxiety is more difficult to figure out. There seems to be a connection between anxiety and seizures. ${ }^{6}$ However, this association has been less well-studied than other mood problems. Gabbs and Barry ${ }^{2}$ stated that the rate of anxiety was $13.3 \%$ in the general population. In persons with epilepsy, up to $52 \%$ also reported symptoms of anxiety. This may mean that anxiety occurs 4 times more often in people with epilepsy.

\section{WHEN ILLNESSES OVERLAP, BOTH NEED TO BE} TREATED When people have both epilepsy and depression, studies show that the depression correlates more strongly with a poor quality of life than the frequency of the seizures. ${ }^{3}$ A person with epilepsy needs medication in order to prevent seizures. If depression is also present, medication may be needed for this as well.

It has long been known that some medicines that treat seizures also treat mood problems. Carbamazepine, lamotrigine, and valproate are a few of the seizure medications that also have a positive effect on mood. 
These medications work in a common way: they increase serotonin levels (serotonin is a neurotransmitter). Higher serotonin levels seem to help to decrease seizures and to improve mood.

In situations where depression (or anxiety) has been identified as a comorbid illness, a neurologist may ask for help from a psychiatrist. With all of the available medications for depression and anxiety, it may be difficult to know which is best for an individual. In addition, the person might need psychotherapy, which is often overseen by a psychiatrist. In other words, a team approach may be needed in order to optimize the person's epilepsy, mood problem, and quality of life.

Epilepsy, depression, anxiety, and bipolar disorder commonly coexist. Although there are many possible explanations for why these disorders are comorbid, it is becoming increasingly evident that these conditions require treatment in order for the patient to achieve the best quality of life. Some AEDs are effective for more than one illness: in some instances, selection of one of these agents may result in improvements in more than one condition. For other patients, combination therapy may be required. Some people will need psychotherapy in order to have the best results. A team approach that involves the neurologist, psychiatrist, and psychologist may help to optimize the evaluation and treatment of people with epilepsy and mood disorders.
FOR MORE INFORMATION

AAN Patients and Caregivers site

http://patients.aan.com

Citizens United For Research In Epilepsy (CURE)

http://www.cureepilepsy.org

Epilepsy Foundation

http://www.epilepsyfoundation.org

Family Caregiver Alliance/National Center on Caregiving

http://www.caregiver.org

\section{REFERENCES}

1. Karceski S. Epilepsy and mood. Neurology 2010;75:e12-e15.

2. Gabbs MG, Barry JJ. The link between mood disorders and epilepsy: why is it important to diagnose and treat? Adv Stud Med 2005;5:S572-S578.

3. Gilliam FG, Mendiratta A, Pack AM, Bazil CW. Epilepsy and common comorbidities: improving the outpatient epilepsy encounter. Epileptic Disord 2005;7(suppl 1):27-33.

4. Kanner AM. Depression in epilepsy: a neurobiologic perspective. Epilepsy Curr 2005;5:21-27.

5. Ettinger AB, Reed ML, Goldberg JF, Hirschfeld RM. Prevalence of bipolar symptoms in epilepsy vs other chronic health disorders. Neurology 2005;65:535-540.

6. Beyenberg S, Mitchell AJ, Schmidt D, Elger CE, Reuber M. Anxiety in patients with epilepsy: systematic review and suggestions for clinical management. Epilepsy Behav 2005;7: 161-171. 


\title{
Neurology
}

\author{
Epilepsy and mood: Update \\ Steven Karceski \\ Neurology 2013;81;e168-e171 \\ DOI 10.1212/01.wnl.0000437698.06686.6c
}

This information is current as of November 25, 2013

Updated Information \& Services

References

Subspecialty Collections

Permissions \& Licensing

Reprints including high resolution figures, can be found at: http://n.neurology.org/content/81/22/e168.full

This article cites 9 articles, 4 of which you can access for free at: http://n.neurology.org/content/81/22/e168.full\#ref-list-1

This article, along with others on similar topics, appears in the following collection(s):

All Epilepsy/Seizures

http://n.neurology.org/cgi/collection/all_epilepsy_seizures All Psychiatric disorders

http://n.neurology.org/cgi/collection/all_psychiatric_disorders Antiepileptic drugs

http://n.neurology.org/cgi/collection/antiepileptic_drugs

Depression

http://n.neurology.org/cgi/collection/depression

Information about reproducing this article in parts (figures,tables) or in its entirety can be found online at:

http://www.neurology.org/about/about_the_journal\#permissions

Information about ordering reprints can be found online:

http://n.neurology.org/subscribers/advertise

Neurology ${ }^{\circledR}$ is the official journal of the American Academy of Neurology. Published continuously since 1951, it is now a weekly with 48 issues per year. Copyright () 2013 American Academy of Neurology. All rights reserved. Print ISSN: 0028-3878. Online ISSN: 1526-632X.

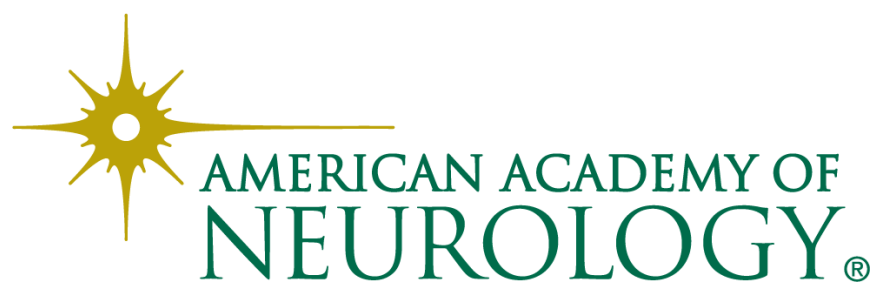

